\title{
Investigation of wear behavior of aged and non-aged SiC-reinforced AlSi7Mg2 metal matrix composites in dry sliding conditions
}

\author{
Yahya Hışman Çelik ${ }^{1}$ Mehmet Emin Demir ${ }^{1}$ - Erol Kilickap ${ }^{2} \cdot$ Ali Kalkanli $^{3}$
}

Received: 24 December 2018 / Accepted: 18 November 2019 / Published online: 26 November 2019

(c) The Brazilian Society of Mechanical Sciences and Engineering 2019

\begin{abstract}
Metal matrix composites (MMCs) with their splendid mechanical properties have been specifically designed for use in fields such as aerospace and aviation. The presence of hard ceramic particles in MMC increases the hardness of the matrix product and decreases its coefficient of friction. Therefore, the wear resistance is improved. Moreover, the mechanical properties of these composite materials can be improved by applying heat treatments. In this study, AlSi7Mg2 MMCs with 15 wt $\% \mathrm{SiC}$ reinforcement were produced by squeeze casting technique. Some of the composites were aged by heat treatment. Hardness values of aged and non-aged composites were compared. In addition, abrasive wear behaviors of these composites were investigated on pin-on-disk device, depending on the load (7, 12 and $17 \mathrm{~N})$, the sliding speed $(0.2,0.3 \mathrm{and} 0.4 \mathrm{~m} / \mathrm{s})$ and the sliding distance $(700,1000$ and $1300 \mathrm{~m})$. Worn surfaces were also analyzed by scanning electron microscopy (SEM). As a result of the analyses, it was determined that both the hardness values and the wear resistance were higher in the composites subjected to aging treatment. Furthermore, it was observed that the increase in the applied load led up to the weight loss. The increase in the sliding distance increased both friction coefficient and weight loss. The increase in sliding speed also made way for the friction coefficient but ensured less weight loss. When SEM images were examined, it was ascertained that deformation and tribo-surface formation had a significant effect on weight losses.
\end{abstract}

Keywords Aging $\cdot$ Composite $\cdot \mathrm{SiC} \cdot$ Squeeze casting $\cdot$ Wear

\section{Introduction}

Aluminum and its alloys are commonly used in many different transport industries, from space to marine, due to their high strength, low specific gravity and ability to adapt to environmental factors. Although the use of these alloys is considered advantageous in many respects (lightness, strength/weight ratio, availability, low price, etc.), its utilization in machine elements is limited due to its low resistance to abrasion. Machine elements with low abrasion resistance wear off seriously over time due to friction and become unusable. This situation causes $1.6 \%$ loss of the gross national product of the developed countries; for example, in the USA, there is financial loss over 100 billion dollars annually, depending on friction and wear. The magnitude of financial losses as a consequence of friction and wear is due to the severe wear of few parts, which disrupts the entire mechanical system [1]. Thus, the demand for producing new materials having more abrasion resistance and better tribological properties has led to the development of aluminum MMCs [2]. Hard ceramic particles such as SiC, 
$\mathrm{Al}_{2} \mathrm{O}_{3}$ and $\mathrm{B}_{4} \mathrm{C}$ are added to the ductile matrix material in order to increase abrasion resistance of the aluminum alloys [3]. This situation also provides significant improvements in the particle/matrix interface strength [4]. These improvements include physical properties such as thermal expansion, density and mechanical properties such as tensile and compressive strengths, creep and tribological behaviors. Particularly in wear behavior, various factors such as load, sliding speed, sliding distance, abrasive size, slope angle of abrasive particles, size and percentage of dispersoid phase are also very important in addition to the physical, chemical and mechanical properties of composites [5, 6]. This has led researchers to focus on MMCs with good physical, chemical and mechanical properties. Umanath et al. [7] investigated the wear behavior of $\mathrm{SiC}$ - and $\mathrm{Al}_{2} \mathrm{O}_{3}$-reinforced $\mathrm{Al} 6061$ MMCs using both experimental and statistical regression and variance analyses (ANOVA). They determined that high reinforcement volume ratio, low load and rotational speed reduced the wear rate. They emphasized that the reinforcement volume ratio acts as a more important factor than other parameters. Jinfeng et al. [8] investigated the effect of graphite reinforcement and grain size on the friction and wear properties of Al matrix composites with $40 \% \mathrm{SiC}$ and $5 \%$ graphite reinforcement developed by the squeeze casting process. It has been found that $10 \mathrm{wt} \%$ of $\mathrm{SiC}$ and $3 \mathrm{wt} \%$ of B4C hybrid composites have enhanced tribological properties. They determined that the graphite reinforcement reduced the friction coefficient of the composites and promoted the abrasion resistance between 170 and 340 times. Rao and Das [9] investigated the effect of $\mathrm{SiC}$ and sliding speed on wear behavior of aluminum alloy and its composites. Hekner et al. [10] studied the wear behaviors of $\mathrm{SiC}-, \mathrm{SiC} /$ carbon nanotube $(\mathrm{CN})$ - and $\mathrm{SiC} /$ glassy carbon-reinforced $\mathrm{Al}$ matrix composites produced by mechanical alloying and hot pressing at $25^{\circ} \mathrm{C}$ and $450{ }^{\circ} \mathrm{C}$ separately. They observed that the presence of both carbon forms significantly reduced wear in comparison with composites which do not include carbon. Veeresh Kumar et al. [11] compared the mechanical and tribological properties of $\mathrm{Al} 6061$ matrix composites reinforced with $\mathrm{SiC}(2,4$ and $6 \mathrm{wt} \%$ ) and unreinforced alloys produced by liquid metallurgy techniques. They found out that the tensile strength and wear resistance of composites were higher than $\mathrm{Al}$ 6061 alloy. Shorowordi et al. [12] investigated the effect of different contact pressures (0.75-3.00 MPa) on aluminum composites with $13 \mathrm{wt} \% \mathrm{~B}_{4} \mathrm{C}$-reinforced $\mathrm{Al}$ and $13 \mathrm{wt} \%$ $\mathrm{SiC}$-reinforced $\mathrm{Al}$, which were abraded against commercial phenolic brake fluids, under dry sliding conditions. Padmavathia and Ramakrishnan [13] produced Al 6061 matrix composites reinforced with multilayer carbon nanotubes (SiCNTs) and SiC by stir casting method. They conducted friction and wear experiments of composites on a pin-ondisk device. Uvaraja [14] investigated the wear behavior of
$\mathrm{Al} 6061$ matrix composites reinforced with $\mathrm{B}_{4} \mathrm{C}$ and $\mathrm{SiC}$ on the pin-on-disk device under dry sliding conditions, depending on the parameters such as applied load, sliding speed, reinforcement ratio and sliding distance. Al 6061 matrix composites, which have a homogeneously dispersed hardphase $\mathrm{SiC}$ and $\mathrm{B}_{4} \mathrm{C}$ particles, had higher hardness than unreinforced alloys. It was detected that $10 \mathrm{wt} \% \mathrm{SiC}$ and $3 \mathrm{wt} \%$ $\mathrm{B}_{4} \mathrm{C}$ hybrid composites show better tribological properties. Uthayakumar et al. [15] compared the friction and wear behavior of the $\mathrm{Al}$ hybrid composites reinforced with 5\% $\mathrm{SiC}$ and 5\% B4C with the unreinforced alloys developed by the stir casting process. Erturun and Karamış [16] examined friction and wear behavior of reciprocatingly extruded 5\% SiC-reinforced Al 6061 matrix composites in lubricated and dry conditions and compared with the unreinforced alloy. They detected that there was a constant relationship between wear resistance, weight loss and hardness. They also observed that weight loss in lubricated conditions was less than that of dry conditions. The mass loss was found to be promoted with increasing the number of passes and load. In the all applied loads, they determined that the abrasion resistance initially increased and decreased, respectively. Karamış et al. [17] investigated the friction and wear behavior of SiC-reinforced $\mathrm{Al}$ matrix composites that are produced by reciprocating extrusion method, depending on the sliding distance, load and number of passes. They determined that the experimental density of the composites was lower than that of theoretical density. The maximum weight loss in both lubricated and dry sliding conditions was obtained from $50 \mathrm{~N}$ load and one pass.

The uses of reinforcement elements are truly crucial to improve the properties of aluminum-based materials. In addition, properties of these materials can be also improved by heat treatment such as aging. In this way, these materials are heavily demanded both scientifically and technologically. When a certain reinforcement substance is added to a heat-treatable aluminum alloy matrix, both the composite and the alloy reflect superior aging characteristics [18]. Das et al. [19] applied T6 heat treatment to the $15 \%$ SiC-reinforced Al 7075 matrix composites which were produced by stir casting method. They studied the porosity, density, stiffness and wear behavior of the composites. By using Taguchi method, they determined that the parameters of $30 \mathrm{~N}$ load and 400 revolutions per minute were suitable values for wear rate. By using (ANOVA) analysis of variance, they also figured out that the load was effective on the wear rate, and the sliding speed was an insignificant parameter. Lin and Liu [20] investigated the effect of aging on wear behaviors by aging $\mathrm{Al}$ alloys and $\mathrm{SiC}$-reinforced aluminum composites at different temperatures. They observed that the aging temperature and duration of SiC-reinforced aluminum composites were essential factors for the wear rate. They also determined that high temperature or long aging time provided better wear resistance. Meyveci et al. [21] examined the wear 
behaviors of aged aluminum $\mathrm{Al} 2024$ and $\mathrm{Al} 6063$ alloys. Al 2024 alloys had higher hardness values than $\mathrm{Al} 6063$ alloys. It was determined that aged composite had higher hardness values than the untreated composite. They also found that the wear resistance of the $\mathrm{Al} 6063$ alloy was higher than that of Al 2024 alloy and consequently leads to a lesser mass loss.

It has been revealed that many studies related to $\mathrm{Al}$ matrix composite materials have been carried out so far. However, both composites produced by using different matrix materials and the aging process have not led to a decrease of interest in this topic. In this study, hardness and wear behaviors of aged and non-aged $\mathrm{SiC} / \mathrm{AlSi} 7 \mathrm{Mg} 2 \mathrm{MMCs}$ produced by squeeze casting method were investigated.

\section{Material and method}

\subsection{Composites production}

$\mathrm{Al}$ alloy was used as matrix material because of its suitability for the squeeze casting. As a reinforcement material, silicon carbide (SiC) particles having 10-40 $\mu \mathrm{m}$ size were selected to obtain good interfacing with the matrix alloy. The reason for using different particle sizes is directly related to the fact that large particles enable to obtain a homogeneous mixture and small particles increase the strength of bonding [22]. The density of $\mathrm{SiC}$ to be used as reinforcement material is $2.80 \mathrm{~g} / \mathrm{cm}^{3}$. This provides significant advantages for the specific strength values of the composites.

In the preparation of matrix material, initially aluminum with $99.9 \%$ purity was added to the ETIAL-140 alloy in order to reduce Si ratio to $7 \%$. It was necessary to have sufficient time to extend the solidification range of the matrix material and to sufficiently wet the reinforcement by the matrix alloy. When the particles cannot be well wetted by the matrix in particle-reinforced composites, the mechanical properties of Al MMCs are adversely affected. To increase the wettability of these composites and to provide excellent bonding between the ceramic and the metal matrix, reactive alloy elements such as $\mathrm{Mg}, \mathrm{Ca}$, $\mathrm{Ti}$ or $\mathrm{Zr}$ were also added into the matrix [23, 24]. Melting process was carried out in the induction furnace having a capacity of $2 \mathrm{~kW}$ power and $1000{ }^{\circ} \mathrm{C}$. AlSi7Mg2 alloy was obtained by making the slag removal process at approximately $550{ }^{\circ} \mathrm{C}$ to prevent the formation of unwanted structures in the interior after the melting of the matrix alloy was carried out. The chemical compositions of the matrix material are given in Table 1.

In addition to reinforcement element, the $\mathrm{SiC}$ reinforcement having a particle size of $10-40 \mu \mathrm{m}$ was added in the molten matrix material at a speed of about $15 \mathrm{~g} / \mathrm{min}$ until it was $15 \%$ by weight. At this stage, the material was in the liquid-solid range and the mixing was carried out with a graphite rod. In the mixing process, the mixer was moved up and down in the induction furnace to ensure the homogenous particle distribution. After the addition of the particle, the furnace was turned off to get liquid/solid mixture; by this means, reinforcement/matrix interface formation was provided. The mixing process continued until the melt became dough by mechanical force. And the temperature of the composite material was increased up to $750{ }^{\circ} \mathrm{C}$. At this temperature, the molten metal was poured into the mold, a pressure of $100 \mathrm{MPa}$ was applied and the material was kept under pressure until it gets solidified. Schematic view of vertical squeeze casting is given in Fig. 1. The composite material produced by the squeeze casting method was removed from the mold. The diameter and length of this AlSi7Mg2 MMC were $90 \mathrm{~mm}$ and $150 \mathrm{~mm}$, respectively.

To improve the mechanical properties of $15 \%$ SiC-reinforced composites, MMC composites were subjected to homogenization and aging. In homogenization heat treatment, composites were dissolved at $550{ }^{\circ} \mathrm{C}$ for $5 \mathrm{~h}$ and then quenched. Later, the oversaturated composites was stabilized by heating at low temperature $\left(8 \mathrm{~h}\right.$ at $\left.185^{\circ} \mathrm{C}\right)$.

The heat treatment conditions and hardness values of $15 \%$ SiC-reinforced AlSi7Mg2 MMCs having $228 \mathrm{MPa}$ tensile

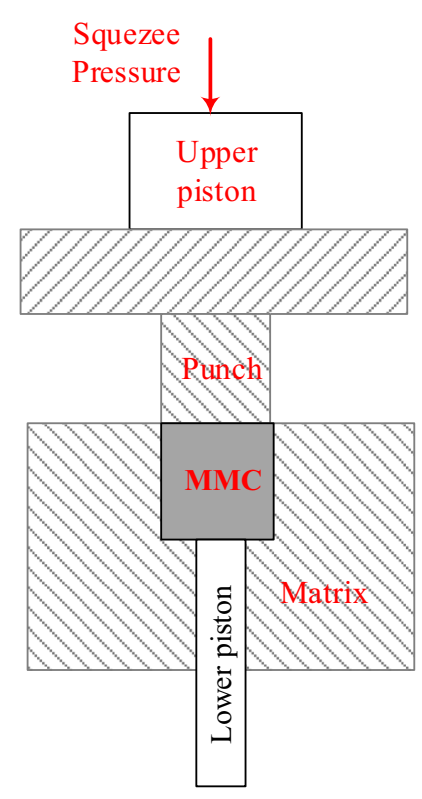

Fig. 1 Schematic view of vertical squeeze casting
Table 1 Chemical composition of AlSi7Mg2 matrix alloy (\%)

\begin{tabular}{lllllllll}
\hline $\mathrm{Mg}$ & $\mathrm{Zn}$ & $\mathrm{Cu}$ & $\mathrm{Fe}$ & $\mathrm{Si}$ & $\mathrm{Ni}$ & $\mathrm{Co}$ & $\mathrm{Ti}$ & $\mathrm{Al}$ \\
\hline 2 & 0.11 & 0.13 & 0.54 & 7 & 0.074 & 0.116 & 0.086 & 89.944 \\
\hline
\end{tabular}


Table 2 Heat treatment conditions and hardness of $15 \%$ $\mathrm{SiC} / \mathrm{AlSi} 7 \mathrm{Mg} 2 \mathrm{MMC}$

\begin{tabular}{llllc}
\hline Heat treatment & Solution treatment & Quench condition & Aging treatment & Hardness (BH) \\
\hline As-received & - & - & - & 95 \\
Solution treated & $5 \mathrm{~h}$ at $550^{\circ} \mathrm{C}$ & Water quenched & - & 97 \\
Aged & $5 \mathrm{~h}$ at $550^{\circ} \mathrm{C}$ & Water quenched & $8 \mathrm{~h}$ at $185^{\circ} \mathrm{C}$ & 116 \\
\hline
\end{tabular}

Fig. 2 Optical views of composites through a microscope

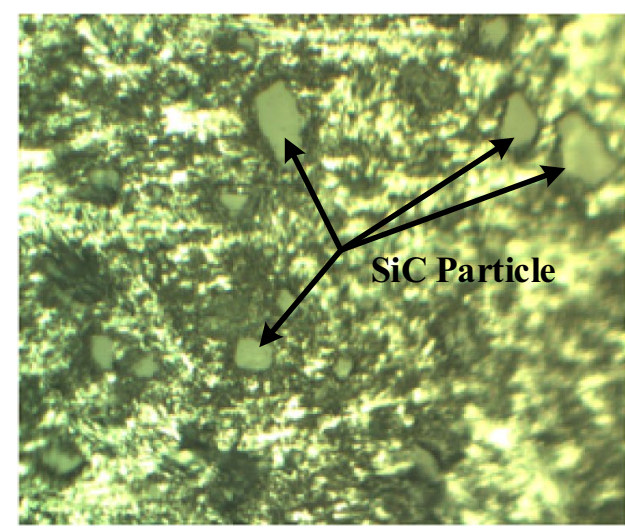

(a) Non-aged $\mathrm{SiC} / \mathrm{AlSi} 7 \mathrm{Mg} 2$ composites

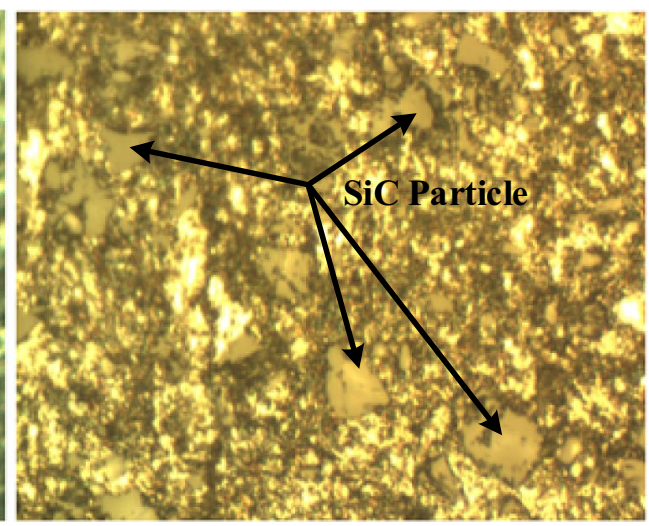

(b) Aged SiC/AlSi7Mg2 composites

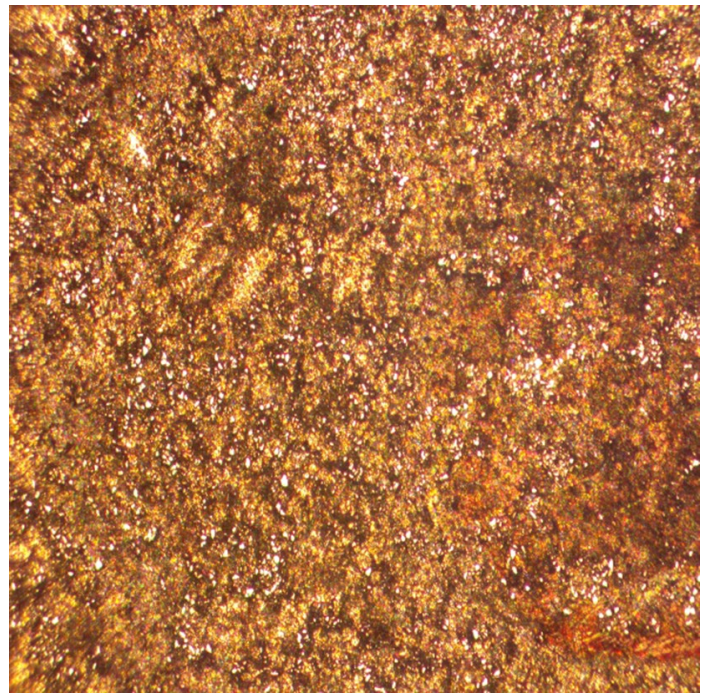

Fig. 3 Homogenous distribution of $\mathrm{SiC}$ particles in matrix

strength are given in Table 2. The $\mathrm{SiC}$ particle distributions of aged and non-aged composites are also given in Fig. 2. The homogeneous distribution is also given in Fig. 3.

\subsection{Wear test}

The centers of the composites were drilled with a 5-mmdiameter drill to perform the wear tests of aged and non-aged composites. The drilled composites were fixed to the pinon-disk wear device (Turkyus brand) by screwing and were ready for the experiment. Under the application arm of the wear device, the abrasive pink grinding stone was attached and the determined weight was placed on application arm. Then, the wear time was entered on the device screen, and the test was launched. The experiments were conducted with regard to the combinations of different loads $(7 \mathrm{~N}, 12 \mathrm{~N}$ and $17 \mathrm{~N})$, sliding speeds $(0.2,0.3$ and $0.4 \mathrm{~m} / \mathrm{s})$ and sliding distances $(700,1000$ and $1300 \mathrm{~m})$ in dry sliding conditions. At the end of each experiment, the composites were weighed on the precision scale (RADWAG brand with a sensitivity of $0.001 \mathrm{mg}$ ); and the final weights were calculated. The wear test device image and test setup are given in Fig. 4.

\section{Results and discussion}

In the wear behavior; the sliding distance, applied load, lubrication status, sliding time and properties of material pair are very pivotal to take into consideration. In the wear device, these parameters can be kept under control. However, the friction coefficient varies depending on the parameters such as the formation of the tribo-surface, the mass loss, the deformation and the heat released from the metal/abrasive part contact during friction. Friction coefficients and forces of SiC-reinforced AlSi7Mg2 MMCs were measured by the wear device during wear tests. The friction coefficients of the aged and non-aged composites measured by the device are given in Fig. 5.

It can be seen that the graphs in Fig. 5 are quite similar. The only difference between the graphs is that the coefficient of friction and the fluctuations change during friction. Initially, friction coefficients increased. This increase 
Fig. 4 Wear test device image and test setup
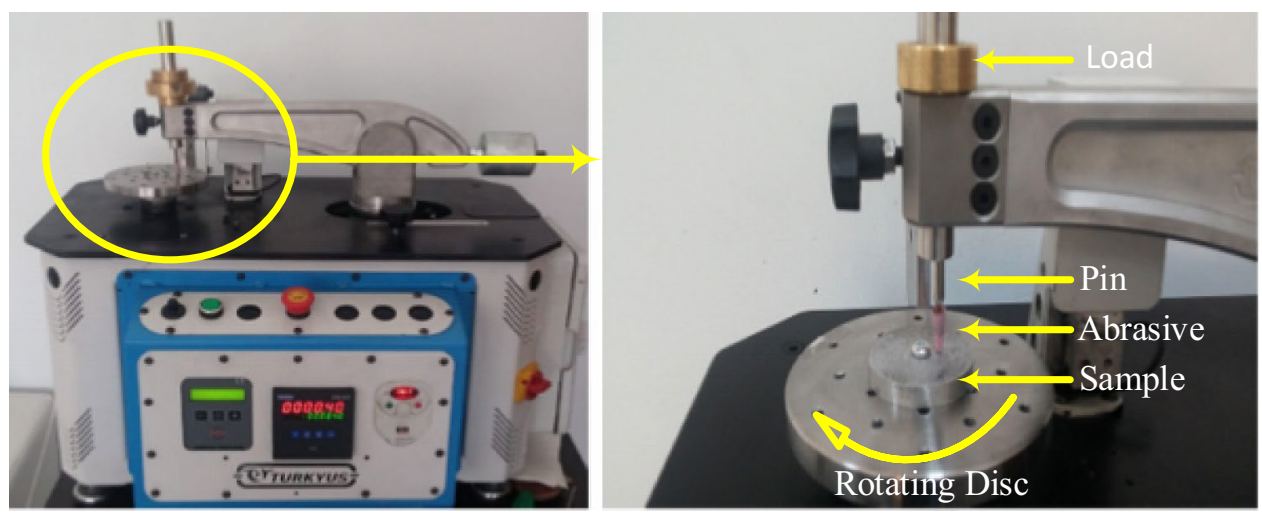

Fig. 5 Variation in the friction coefficient of aged and non-aged composites depending on load and sliding speed for a sliding distance of $700 \mathrm{~m}$

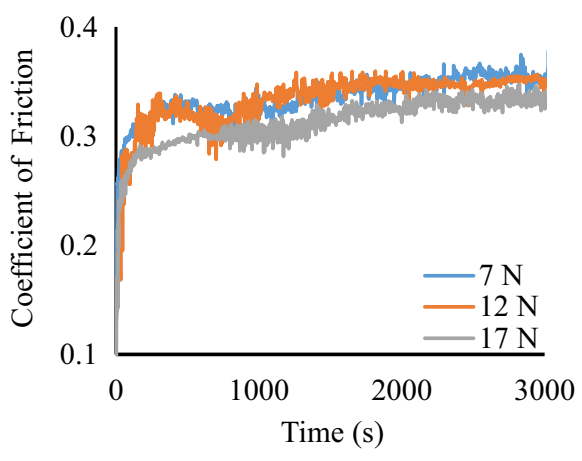

Non-aged; Sliding speed: $0.2 \mathrm{~m} / \mathrm{s}$

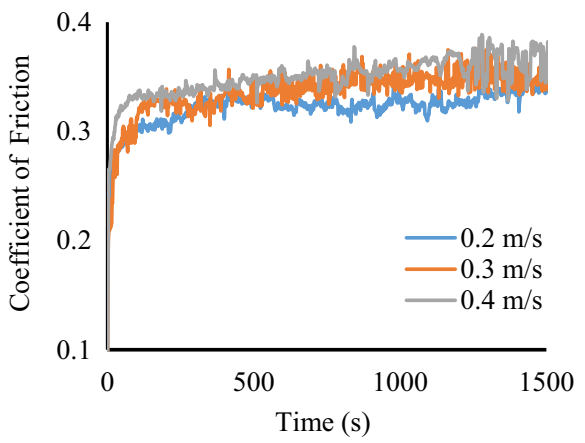

Non-aged; Load: $7 \mathrm{~N}$

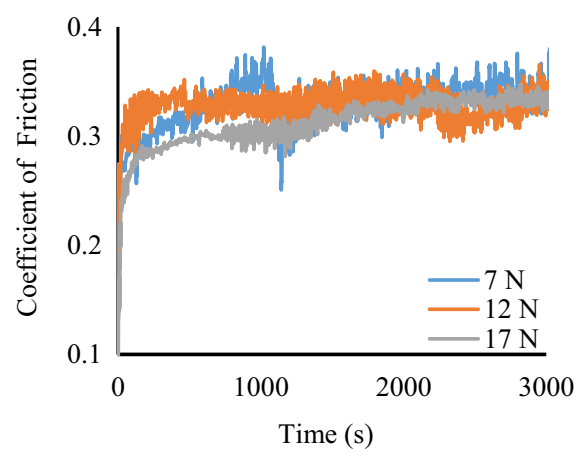

Aged: Sliding speed: $0.2 \mathrm{~m} / \mathrm{s}$

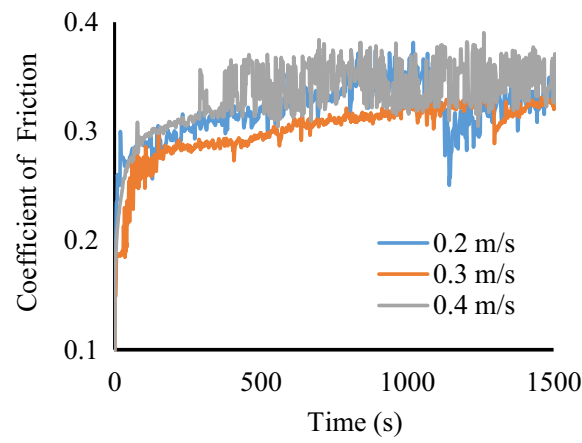

Aged; Load: $7 \mathrm{~N}$ in the friction coefficient was very low as the sliding time increased. This situation was related to the change in initial surface roughness of the composite during friction. On the other hand, it was related to the compatibility of abrasive and composite material. In addition, in some experiments, fluctuations were small, but in some, they were high, and in some experiments, there was an increase after a certain sliding time. The increase in these fluctuations was brought about by the decrease in the force, submerging of abrasive in composite material and contact of abrasive with $\mathrm{SiC}$ reinforcement in the composite. Considering the fluctuations, the analysis of the average friction coefficients for the determination of friction coefficient values is gaining importance.
The average friction coefficient changes of aged and nonaged composites depending on load, sliding speed and sliding distance are shown in Fig. 6.

In all the wear parameters, it was determined that the friction coefficients of the aged composite were lower than those of non-aged composite. With the increase in the applied load in abrasive wear tests, it was observed that the friction coefficient decreased in both aged and non-aged composites. In some studies, it was observed that the friction coefficient increased due to the increase in the load [25-27], whereas in others, it was observed that it decreased as in our study [28, 29]. This is due to the formation of the tribo-surface. The tribo-surface 
Fig. 6 Variation in friction coefficient of aged and nonaged composites depending on applied load, sliding distance and time

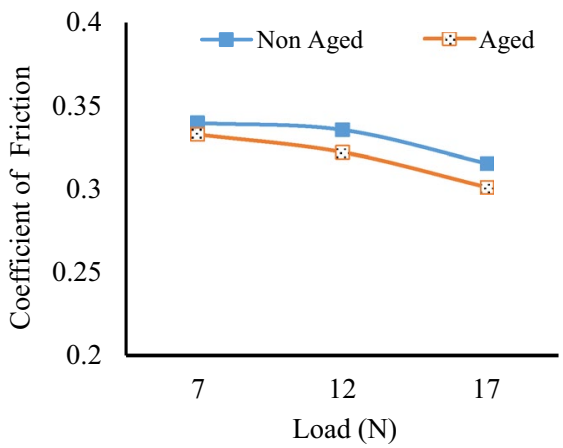

(a) Speed: $0.2 \mathrm{~m} / \mathrm{s}$; Sliding Distance: $700 \mathrm{~m}$

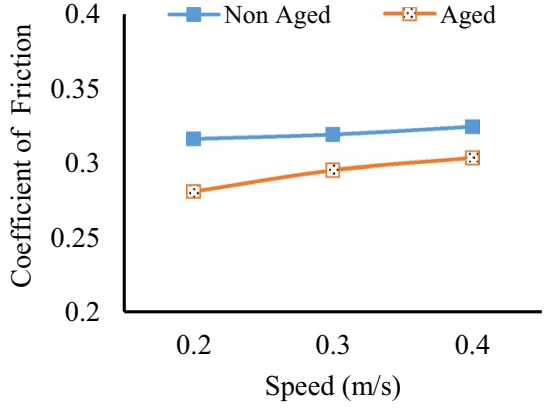

(b) Load: $17 \mathrm{~N}$; Sliding Distance: $1000 \mathrm{~m}$

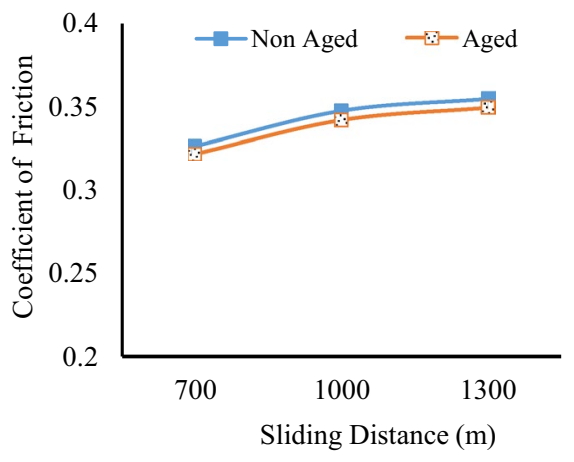

(c) Sliding Speed: $0.3 \mathrm{~m} / \mathrm{s}$; Load: $12 \mathrm{~N}$

formed between the abrasive piece and the sliding surface reduces the friction coefficient. In other words, when the load increases, the nominal contact area between the pin and the opposite surface increases, so an increase in the contact temperature results in a softening of the surface; therefore, sliding movement between the contact surfaces causes reduction in the friction coefficient [29]. It was observed that the decrease in the friction coefficient with increasing the applied load from 7 to $12 \mathrm{~N}$ was less than raising the load from 12 to $17 \mathrm{~N}$. Considering the sliding speed, the friction coefficient of both aged and non-aged composites increased with increasing the sliding speed. The friction coefficient of the aged composite was higher than that of the non-aged composite. It was understood that the effect of increasing sliding speed on the aged composite was higher. The main factor in the increase in friction coefficient depending on sliding speed was that the $\mathrm{SiC}$ reinforcements in the composites were squeezed out onto the mating surfaces forming mechanically mixed layer [25]. For the sliding distance, it was observed that the friction coefficient increased linearly for both aged and non-aged composites with increasing sliding distance. This was thought to be a function of the heat during friction or of pulling out of $\mathrm{SiC}$ particles from mechanically abraded parts between the contact surfaces [25]. It was seen that the increase in friction coefficient decreased with increasing sliding distance.
The mass losses due to the applied load, sliding speed and sliding distance of the aged and non-aged composites are given in Fig. 7.

Figure 7a shows that mass losses increased for both aged and non-aged composites due to the increase in applied load. Although the decrease in mass loss is expected due to the reduction in friction coefficient, it is thought that mass loss increases because $\mathrm{SiC}$ pieces on the tribo-surface are ruptured from the softening material with increasing surface temperature. Similar studies by some researchers $[30,31]$ seemed to be consistent with these results. In Fig. 7b, it was observed that mass losses decreased due to increasing sliding speed contrary to applied load. Unlike our study, Chowdhury and Rahaman determined that increasing sliding speed resulted in decreased friction coefficient and increased weight loss [32]. With increasing sliding speed, it could be said that the mass loss was reduced due to shorter contact time of abrasive or formation of tribo-layer at the contact surfaces [25, 33]. In Fig. 7c, it was determined that the mass loss increased with increasing sliding distance [34, 35]. Compared to other sliding distances, a significant mass loss occurred at a sliding distance of $1300 \mathrm{~m}$. In all three conditions, the mass losses of the aged composites were determined to be less.

It was observed that the wear loss in aged composites was less in all experimental conditions. To interpret this in detail, it is necessary to analyze the SEM images of 
Fig. 7 Mass loss of aged and non-aged composites

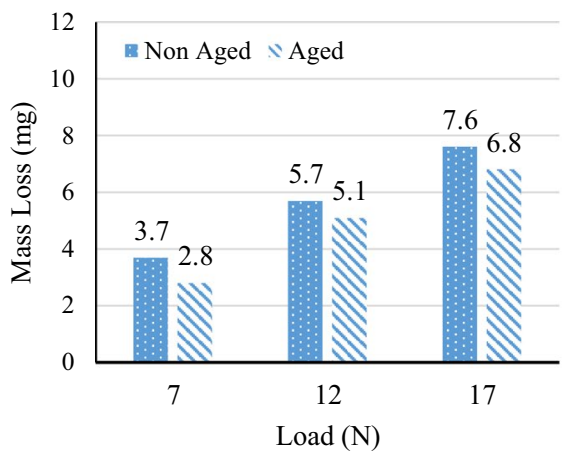

(a) Speed: $0.2 \mathrm{~m} / \mathrm{s}$, Sliding distance: $700 \mathrm{~m}$

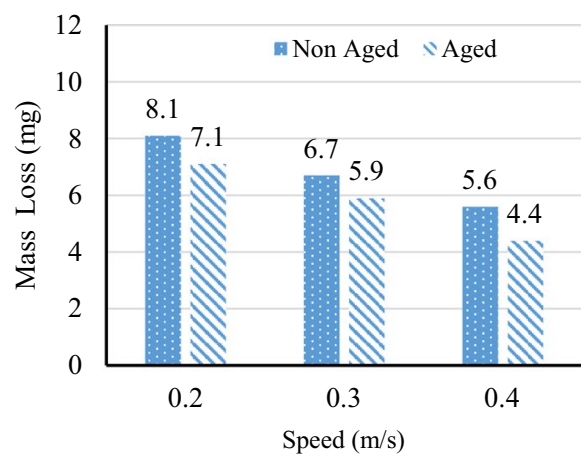

(b) Load: $17 \mathrm{~N}$, Sliding distance: $1000 \mathrm{~m}$

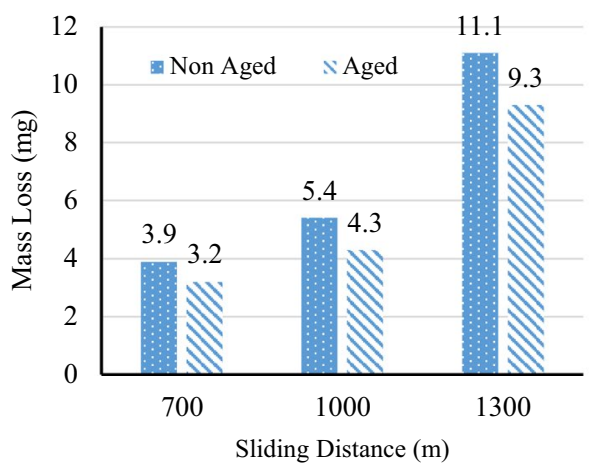

(c) Speed: $0.3 \mathrm{~m} / \mathrm{s}$, Load: $12 \mathrm{~N}$

the worn surface. The SEM images of the aged and nonaged composites on worn surfaces for an applied load of $12 \mathrm{~N}$, a sliding speed of $0.3 \mathrm{~m} / \mathrm{s}$ and a sliding distance of $1000 \mathrm{~m}$ are given in Fig. 8. In Fig. 8, it can be seen that the wear cavity in the aged composite was less than that of non-aged composite. The wear surface of the aged composite was subjected to less plastic deformation due to the fact that the wear surface was not easily worn (high wear resistance) because, depending on the aging process, precipitation formation increased the strength of the matrix and supported the reinforcement better [20, 36]. However, because the strength value of the non-aged composite was worse than that of aged, more wear cavity width was obtained in the same wear parameter. As the wear width increased, the contact area on the friction surfaces increased. The increase in contact area increased the penetration of the hard particles of the opposite surface into the soft pin surface, while, at the same time, it increased the plastic deformation and deformation of the soft surface. On the other hand, deformation and plastic deformation increased the stresses on the material surface. Due to high stress concentration, plastic deformation occured in roughness and moved away from the surface of the material [37].

\section{Conclusion}

The effects of aging, applied load, sliding speed and sliding distance on the tribological behaviors in MMCs were analyzed, and the following results were obtained;

- It was determined that the hardness of the composites increased with the heat treatment to the composite materials. The hardness of aged composites increased by about $22 \%$ compared to the non-aged composites.

- It was detected that the friction coefficient decreased due to the increase in applied load. It was also observed that the friction coefficient increased with increasing the sliding distance and speed. The effect of load and sliding speed on the friction coefficient was found to be greater than the sliding distance. The friction coefficients of aged composites at minimum and maximum loads were obtained as $0.332 \mu$ and $0.301 \mu$, and those of non-aged composites were obtained as $0.339 \mu$ and $0.315 \mu$, respectively, for $0.2 \mathrm{~m} / \mathrm{s}$ speed and $700 \mathrm{~m}$ sliding distance. The friction coefficients of aged composites at minimum and maximum sliding speeds were found to be $0.281 \mu$ and $0.303 \mu$, and those of non- 

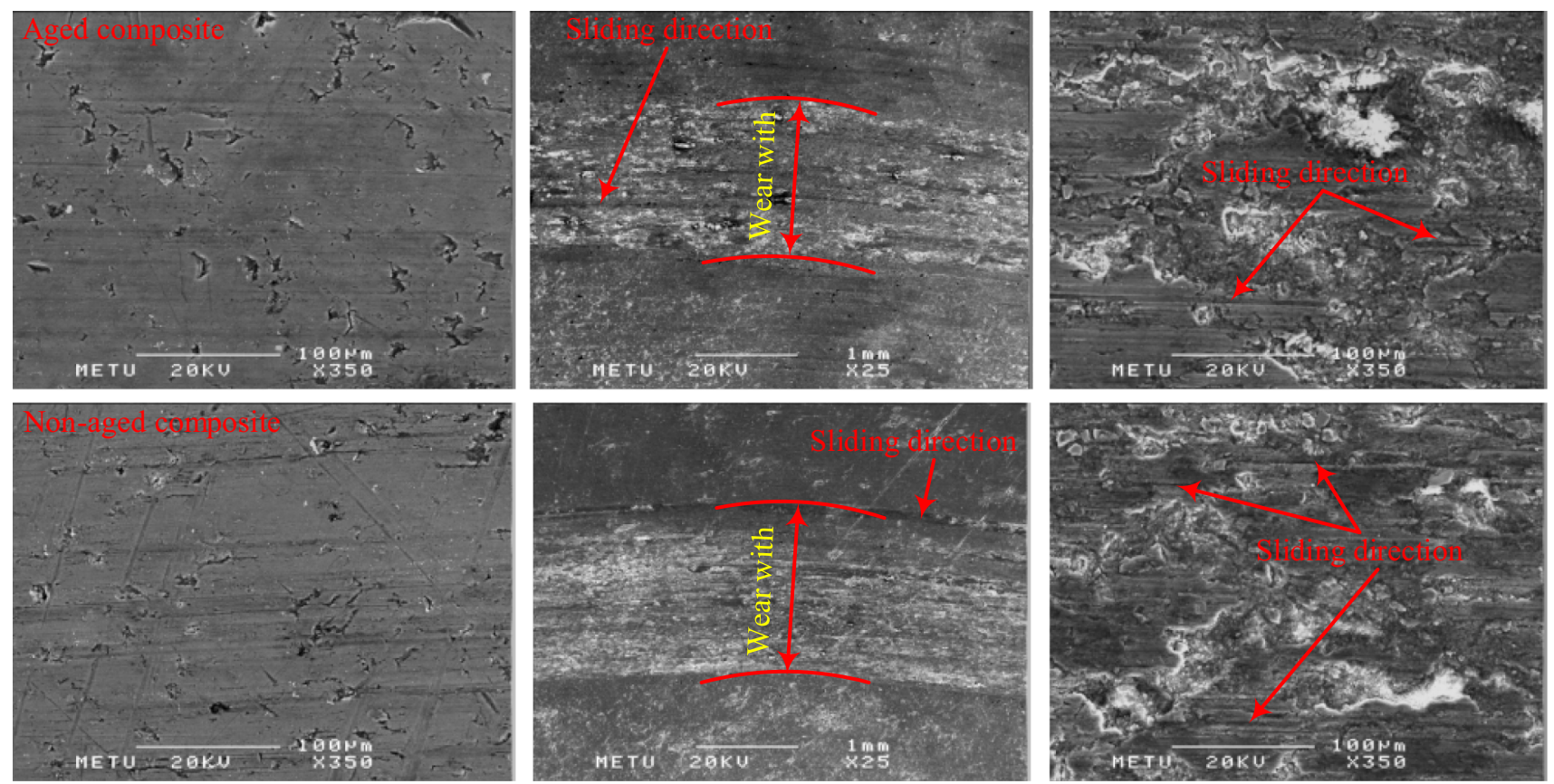

Fig. 8 SEM images of aged and non-aged composites

aged composites were found to be $0.316 \mu$ and $0.324 \mu$, respectively, for $17 \mathrm{~N}$ load and $1000 \mathrm{~m}$ sliding distance.

- It was concluded that the abrasion resistance of aged composites was higher than that of non-aged composites.

- It was seen that the mass losses increased by increasing load and sliding distances, but decreased by increasing sliding speed. The mass loss of aged composites at minimum and maximum loads was obtained as 2.8 and $6.8 \mathrm{mg}$, and that of non-aged composites was obtained as 3.7 and 7.6 , respectively, for $0.2 \mathrm{~m} / \mathrm{s}$ speed and $700 \mathrm{~m}$ sliding distance. The mass losses of aged composites at minimum and maximum sliding distances were found to be 3.2 and $9.3 \mathrm{mg}$, and those of non-aged composites were found to be 3.9 and $11.1 \mathrm{mg}$, respectively, for $0.3 \mathrm{~m} / \mathrm{s}$ sliding speed and $12 \mathrm{~N}$ load.

\section{References}

1. Gavgali M, Totik Y, Sadeler R (2003) The effects of artificial aging on wear properties of AA 6063 alloy. Mater Lett 57:37133721. https://doi.org/10.1016/S0167-577X(03)00168-X

2. Kala H, Mer KKS, Kumar S (2014) A review on mechanical and tribological behaviors of stir cast Aluminum matrix composites. Procedia Mater Sci 6:1951-1960. https://doi.org/10.1016/j.mspro .2014.07.229

3. Basavarajappa S, Chandramohan G, Mahadevan A et al (2007) Influence of sliding speed on the dry sliding wear behaviour and the subsurface deformation on hybrid metal matrix composite. Wear 262:1007-1012. https://doi.org/10.1016/j.wear.2006.10.016
4. Odabaş D, Su Ş (1997) A comparison of the reciprocating and continuous two-body abrasive wear behavior of solution-treated and age-hardened $2014 \mathrm{Al}$ alloy. Wear 208:25-35. https://doi. org/10.1016/S0043-1648(96)07378-4

5. Zheng MY, Wu K, Kamado S, Kojima Y (2003) Aging behavior of squeeze cast $\mathrm{SiC} / \mathrm{AZ} 91$ magnesium matrix composite. Mater Sci Eng A 348:67-75. https://doi.org/10.1016/S0921 -5093(02)00638-X

6. Kaushik NC, Rao RN (2016) Effect of applied load and grit size on wear coefficients of Al6082-SiC-Gr hybrid composites under two body abrasion. Tribol Int 103:298-308. https://doi. org/10.1016/j.triboint.2016.07.018

7. Umanath K, Palanikumar K, Selvamani ST (2013) Analysis of dry sliding wear behaviour of $\mathrm{Al} 6061 / \mathrm{SiC} / \mathrm{Al}_{2} \mathrm{O}_{3}$ hybrid metal matrix composites. Compos Part B Eng 53:159-168. https://doi. org/10.1016/j.compositesb.2013.04.051

8. Jinfeng L, Longtao J, Gaohui W, Shoufu T, Guoqin C (2009) Effect of graphite particle reinforcement on dry sliding wear of SiC/Gr/Al composites. Rare Met Mater Eng 38(11):1894-1898

9. Rao RN, Das S (2011) Effect of SiC content and sliding speed on the wear behaviour of aluminium matrix composites. Mater Des 32:1066-1071. https://doi.org/10.1016/j.matde s.2010.06.047

10. Hekner B, Myalski J, Valle N et al (2017) Friction and wear behavior of $\mathrm{Al}-\mathrm{SiC}(\mathrm{n})$ hybrid composites with carbon addition. Compos Part B Eng 108:291-300. https://doi.org/10.1016/j. compositesb.2016.09.103

11. Veeresh Kumar GB, Rao CSP, Selvaraj N (2012) Studies on mechanical and dry sliding wear of Al6061-SiC composites. Compos Part B Eng 43:1185-1191. https://doi.org/10.1016/j. compositesb.2011.08.046

12. Shorowordi KM, Haseeb ASMA, Celis JP (2006) Tribo-surface characteristics of $\mathrm{Al}-\mathrm{B}_{4} \mathrm{C}$ and $\mathrm{Al}-\mathrm{SiC}$ composites worn under different contact pressures. Wear 261:634-641. https://doi. org/10.1016/j.wear.2006.01.023 
13. Padmavathi KR, Ramakrishnan R (2014) Tribological behaviour of aluminium hybrid metal matrix composite. Procedia Eng 97:660-667. https://doi.org/10.1016/j.proeng.2014.12.295

14. Uvaraja VC (2012) Tribological characterization of stir-cast hybrid composite aluminium 6061 reinforced with $\mathrm{SiC}$ and $\mathrm{B}_{4} \mathrm{C}$ particulates. Eur J Sci Res 76:539-552

15. Uthayakumar M, Aravindan S, Rajkumar K (2013) Wear performance of $\mathrm{Al}-\mathrm{SiC}-\mathrm{B}_{4} \mathrm{C}$ hybrid composites under dry sliding conditions. Mater Des 47:456-464. https://doi.org/10.1016/j.matde s.2012.11.059

16. Erturun V, Karamış MB (2016) The effects of a reciprocating extrusion process on the friction and wear behaviors of AA 6061/ SiC composites. J Mater Res 31:388-395. https://doi.org/10.1557/ jmr.2016.10

17. Karamış MB, Sarı FN, Erturun V (2012) Technology friction and wear behaviors of reciprocatingly extruded $\mathrm{Al}-\mathrm{SiC}$ composite. J Mater Process 212:2578-2585. https://doi.org/10.1016/j.jmatp rotec.2012.07.006

18. Bekheet NE, Galderab RM, Salah MF, Abd El-Azim AN (2002) The effects of aging on the hardness and fatigue behavior of 2024 Al alloy/SiC composites. Mater Des 23:153-159. https://doi. org/10.1016/S0261-3069(01)00072-3

19. Das D, Pattanaik S, Routara BC et al (2017) Dry sliding wear behaviour of $\mathrm{SiC}_{\mathrm{p}}$ reinforced $\mathrm{Zn}-\mathrm{Mg}-\mathrm{Cu}$ based aluminium matrix composite. Mater Today Proc 4:2965-2974. https://doi. org/10.1016/j.matpr.2017.02.178

20. Lin S, Liu K (1988) Effect of aging on abrasion rate in an Al-ZnMg-SiC composite. Wear 121:1-14. https://doi.org/10.1016/00431648(88)90026-9

21. Meyveci A, Karacan I, Çaligülü U, Durmuş H (2010) Pin-ondisc characterization of $2 \mathrm{xxx}$ and $6 \mathrm{xxx}$ aluminium alloys aged by precipitation age hardening. J Alloys Compd 491:278-283. https ://doi.org/10.1016/j.jallcom.2009.10.142

22. Ozben T, Kilickap E, Cakir O (2008) Investigation of mechanical and machinability properties of $\mathrm{SiC}$ particle reinforced Al-MMC. J Mater Process Technol 198:220-225

23. Naidich JV, Chuvashov JN (1983) Wettability and contact interaction of gallium-containing melts with non-metallic solids. J Mater Sci 18:2071-2080. https://doi.org/10.1007/BF00555000

24. Mitra R, Mahajan YR (1995) Interfaces in discontinuously reinforced metal matrix composites. Bull Mater Sci 18:405-434

25. Ravindran P, Manisekar K, Rathika P, Narayanasamy P (2013) Tribological properties of powder metallurgy — processed aluminium self lubricating hybrid composites with $\mathrm{SiC}$ additions. Mater Des 45:561-570. https://doi.org/10.1016/j.matdes.2012.09.015

26. Uvaraja VC, Natarajan N (2012) Optimization of friction and wear behaviour in hybrid metal matrix composites using Taguchi technique. J Miner Mater Charact Eng 11:757-768

27. Moazami-Goudarzi M, Akhlaghi F (2016) Wear behavior of A15252 alloy reinforced with micrometric and nanometric SiC particles. Tribol Int 102:28-37. https://doi.org/10.1016/j.tribo int.2016.05.013

28. Rao RN, Das S (2010) Effect of matrix alloy and influence of SiC particle on the sliding wear characteristics of aluminium alloy composites. Mater Des 31:1200-1207. https://doi.org/10.1016/j. matdes.2009.09.032

29. Lakshmipathy J, Kulendran B (2014) Reciprocating wear behavior of $7075 \mathrm{Al} / \mathrm{SiC}$ in comparison with $6061 \mathrm{Al} / \mathrm{Al}_{2} \mathrm{O}_{3}$ composites. Int J Refract Met Hard Mater 46:137-144. https://doi.org/10.1016/j. ijrmhm.2014.06.007

30. Rana RS, Purohit R, Sharma AK, Rana S (2014) Optimization of wear performance of AA5083/10 wt.\% $\mathrm{SiC}_{\mathrm{p}}$ composites using Taguchi method. Procedia Mater Sci 6:503-511. https://doi. org/10.1016/j.mspro.2014.07.064

31. Rao RN, Das S, Mondal DP, Dixit G (2012) Mechanism of material removal during tribological behaviour of aluminium matrix (Al-Zn-Mg-Cu) composites. Tribol Int 53:179-184. https://doi. org/10.1016/j.triboint.2012.04.017

32. Chowdhury MA, Khalil MK, Nuruzzaman DM, Rahaman ML (2011) The effect of sliding speed and normal load on friction and wear property of aluminum. Int J Mech Mech Eng 11:53-57

33. Ravindran P, Manisekar K, Narayanasamy P et al (2012) Application of factorial techniques to study the wear of Al hybrid composites with graphite addition. Mater Des 39:42-54. https://doi. org/10.1016/j.matdes.2012.02.013

34. Çelik YH, Kilickap E (2019) Hardness and wear behaviours of Al matrix composites and hybrid composites reinforced with $\mathrm{B}_{4} \mathrm{C}$ and SiC. Powder Metall Met Ceram 57:613-622. https://doi. org/10.1007/s11106-019-00023-w

35. Çelik YH, Seçilmiş K (2017) Investigation of wear behaviours of $\mathrm{Al}$ matrix composites reinforced with different $\mathrm{B}_{4} \mathrm{C}$ rate produced by powder metallurgy method. Adv Powder Technol 28:22182224. https://doi.org/10.1016/j.apt.2017.06.002

36. Sawla S, Das S (2004) Combined effect of reinforcement and heat treatment on the two body abrasive wear of aluminum alloy and aluminum particle composites. Wear 257:555-561. https://doi. org/10.1016/j.wear.2004.02.001

37. Rao RN, Das S, Mondal DP, Dixit G (2009) Dry sliding wear behaviour of cast high strength aluminium alloy (Al-Zn-Mg) and hard particle composites. Wear 267:1688-1695. https://doi. org/10.1016/j.wear.2009.06.034

Publisher's Note Springer Nature remains neutral with regard to jurisdictional claims in published maps and institutional affiliations. 